\title{
Monitoring the Activation of Copper-containing Zeotype Catalysts Prepared by Direct Synthesis using In Situ Synchrotron Infrared Microcrystal Spectroscopy and Complementary Techniques
}

Eike C. V. Eschenroeder, ${ }^{1}$ Alessandro Turrina, ${ }^{1}$ A. Lorena Picone, ${ }^{1,+}$ Gianfelice Cinque, ${ }^{2}$ Mark D. Frogley, ${ }^{3}$ Paul A. Cox, ${ }^{4}$ Russell F. Howe ${ }^{5}$ and Paul A. Wright ${ }^{1,{ }^{*}}$

${ }^{1}$ EaStCHEM School of Chemistry, University of St Andrews, Purdie Building, North Haugh, St Andrews, Fife, KY16 9ST, UK.

${ }^{2}$ Diamond Light Source, Harwell Science and Innovation Campus, Didcot, OXı1 oDE, UK

${ }^{3}$ School of Pharmacy and Biomedical Sciences, University of Portsmouth, St. Michael's Building, White Swan Road, Portsmouth, UK PO1 2DT, UK

${ }^{4}$ Department of Chemistry, University of Aberdeen, Meston Building, King's College, Aberdeen AB24 3UE, UK

KEYWORDS: Templating, in situ, synchrotron IR microspectroscopy, CuSAPO STA-7, catalyst

\begin{abstract}
The use of copper polyamine complexes as structure directing agents for microporous solids offers a direct route to the inclusion of $\mathrm{Cu}^{2+}$ complex cations in their pores: upon calcination, this gives active catalysts for the selective catalytic

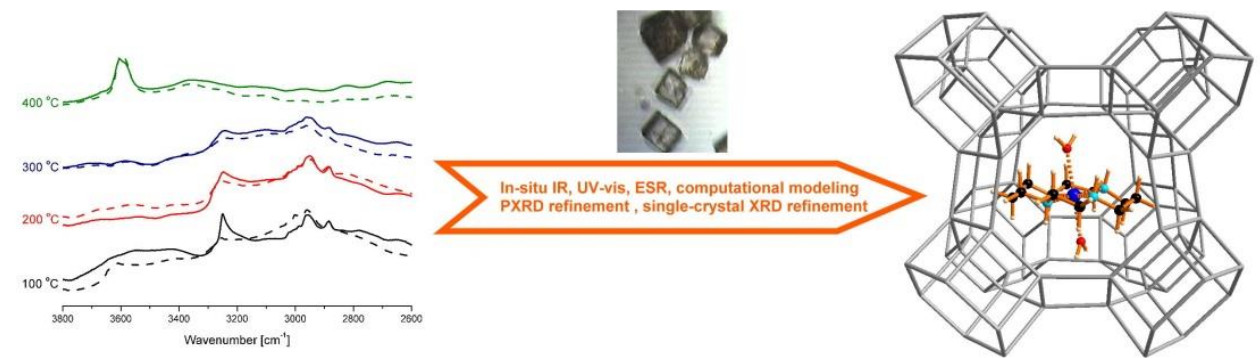
reduction of $\mathrm{NO}$ with $\mathrm{NH}_{3}$. In situ synchrotron IR absorption spectroscopy on crystals of dimensions $25-35 \mu \mathrm{m}$ has been used to monitor the dehydration of the $\mathrm{Cu}^{2+}$-cyclam complex that acts as a co-template for the silicoaluminophosphate SAPO STA-7 and, at higher temperatures $\left(400{ }^{\circ} \mathrm{C}\right)$, the calcination that gives the active catalyst $\mathrm{Cu}, \mathrm{H}-\mathrm{SAPO}$ STA-7. Polarised synchrotron IR microspectroscopy reveals strong alignment of $\mathrm{N}-\mathrm{H}$ bonds of the $\mathrm{Cu}^{2+}$ cyclam in the larger cages of as-prepared STA-7, and complementary X-ray diffraction, ESR and UV-visible spectroscopy and computer simulation indicates that hydrated complexes act as co-templates during crystallisation: dehydration leads to removal of their coordinated water by $200{ }^{\circ} \mathrm{C}$.
\end{abstract}

\section{Introduction}

Small pore zeolites and zeotypes have in recent years found important application as catalysts in the synthesis of olefins from methanol ${ }^{1}$ and, when suitably loaded with copper cations, in the selective catalytic reduction (SCR) of nitric oxide with ammonia. ${ }^{2}$ Whereas the acidcatalysed methanol-to-olefins MTO reaction produces ethylene and propylene, monomers for plastics, the SCR reaction is highly effective for the removal of $\mathrm{NO}$ from the emissions of lean burn automotive engines. SAPO34, the silicoaluminophosphate (SAPO) version of the aluminosilicate zeolite chabazite, ${ }^{3}$ is the zeotype used most commonly in these and related industrial processes and as a result has been studied extensively, including by in situ diffraction and spectroscopies, during MTO and SCR catalysis., ${ }^{4,5}$ SAPO STA-7 has a framework structure closely related to that of SAPO $-34 .^{6}$ Like SAPO-34, it is made of double six-membered rings (D6Rs, with two joined rings of 6 tetrahedrallycoordinated cations and 6 oxygen atoms) linked by four membered rings (4MRs), but the D6Rs are stacked differently in the two different structures and the STA-7 framework has two different types of cage, of different sizes (Figure 1), rather than the single cage type present in SAPO-34. As in SAPO-34, the cages in STA-7 are linked by $8 \mathrm{MR}$ windows, and the SAPO material is a strong solid acid that shows good activity for light olefin 
generation and resistance to coking in the MTO reaction. ${ }^{7}$ Recently, we devised synthetic routes by which each of SAPO-34 and SAPO STA-7 could be synthesised using copper-polyamine complexes as structure directing agents, so that subsequent calcination removed the organic template, leaving $\mathrm{Cu}^{2+}$ cations homogeneously dispersed throughout the cages. ${ }^{8,9}$ The group of Corma have extended this synthetic procedure to SAPO-34 with different compositions..$^{10}$ It has also been shown possible to use the direct synthesis approach to give copper-containing aluminosilicates with the chabazite structure (known as $\mathrm{Cu}-\mathrm{SSZ}-13)^{11,12}$ This approach has important advantages over the conventional ion exchange routes, where the required additional step of cation exchange from solution can lead to poor $\mathrm{Cu}^{2+}$ cation dispersion and, especially for aluminophosphates, to framework damage. Once the amine is removed, the $\mathrm{Cu}^{2+}$ containing SAPO- 34 and SAPO STA-7 and the Cu-SSZ-13 prepared in this way are highly active and selective catalysts. ${ }^{8-12}$

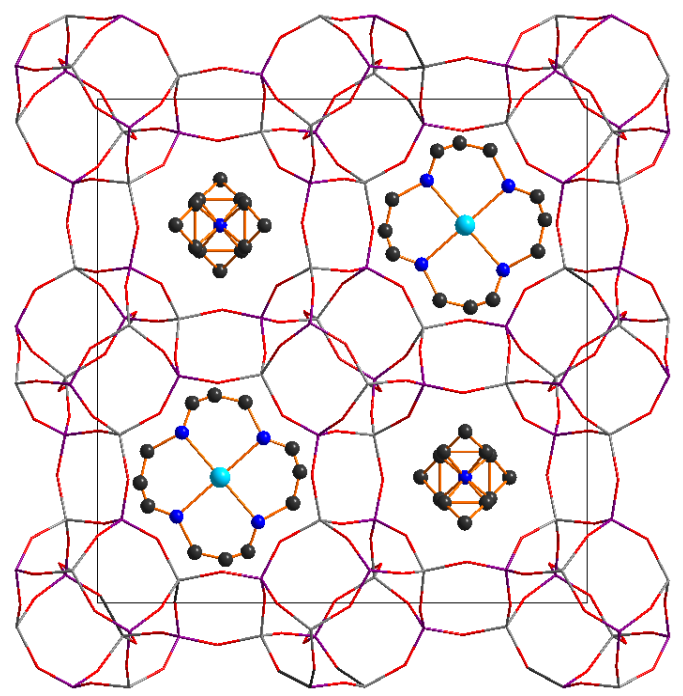

Figure 1. Structure of Cu-SAPO STA-7, viewed down c-axis, with a ball-and-stick representation of disordered $\mathrm{Cu}^{2+}$ cyclam and tetraethylammonium cation co-templates in the large and small cages of the STA-7 framework structure (only bonds shown). $\mathrm{Cu}^{2+}$ cations, cyan; $\mathrm{N}$ atoms, blue; $\mathrm{C}$ atoms, black; $\mathrm{H}$ atoms not shown.)

In order to understand the action of copper-amine complexes as templates and also how they are removed by calcination to leave active catalysts, we have combined in situ single-crystal infrared spectroscopy on Cu-SAPO STA-7 during its activation with a range of other spectroscopic and diffraction measurements. The spectroscopic study of single crystals with dimensions in the tens of microns, with simultaneous monitoring by optical microscopy, has the strong advantage of relating observed changes to individual particles of known geometry and size, rather than to microcrystalline powders where effects could be averaged. In addition, for crystals for which the orientation of the crystallographic lattice can readily be associated with their external morphology, it is possible to use polarised light to investigate the orientations of molecules adsorbed or included within the pores. Such single crystal studies, using vibrational (IR, Raman) ${ }^{13}$ and UVvisible spectroscopies or optical or confocal fluorescence microscopy have provided a wealth of information on detemplation, ${ }^{14}$ adsorption and diffusion, ${ }^{15}$ and catalytic reactions ${ }^{16}$ over microporous materials such as zeolites and zeotypes. Specifically for single-crystal IR, polarised laboratory IR studies by Howe et al. were able to identify the orientation of template molecules within AlPO- $5 .{ }^{17}$ Using the same technique, Schüth et al. were able to determine that adsorbed para-xylene molecules aligned with their long axis parallel to the channels in the centre of the crystals of SAPO- 5 but did not show polarisation effects at the crystal edges, due to effects on the channel structure by twinning within the crystal. ${ }^{18}$ More recent studies have even shown that identifiable carbenium ion intermediates in catalytic reactions can be located and their orientation determined in situ during catalysis, again using polarised synchrotron IR studies. ${ }^{16}$ The advantages of using Synchrotron IR Radiation compared to globar (blackbody emission) sources available in the laboratory is the circa 100x increase in flux density available at the sample in the mid-IR range, i.e. a great improvement in the minimum detection limit allowing high signal-to-noise ratio spectra even on a microscale sample. This is of still greater value when polarised IR is used to obtain direction-dependent spectra in anisotropic systems.

Bearing in mind the strengths and limitations of in situ single-crystal IR spectroscopy combined with optical microscopy, we have chosen to investigate the thermal activation of Cu-SAPO STA-7. Crystals of STA-7 display an elongated tetragonal prism morphology, with the $<100>$ and <ool> faces expressed, that is easily recognisable under the optical microscope. By contrast, the rhombs of SAPO-34 are close to cubic in shape and their orientation is less easily identified or achieved in the IR microscopy experiment. Polarised synchrotron IR spectra measured during the thermal activation of $\mathrm{Cu}$ SAPO STA-7 emphasise the power of this technique to study the behaviour of materials available as single crystals. They indicate the orientation of the hydrated copper cyclam complex within the cages and its dehydration and subsequent decomposition to leave a porous $\mathrm{Cu}, \mathrm{H}-\mathrm{SAPO}$ with catalytically active divalent $\mathrm{Cu}^{2+}$ cations and Brønsted hydroxyl groups. Additional details of the orientation and state of hydration of the complex and its decomposition are available from complementary spectroscopy, X-ray diffraction, thermogravimetric analysis and modelling to give an integrated picture of the activation of microporous solids containing such metal complex templates.

\section{Experimental}


SAPO STA-7 and Cu-SAPO STA-7 samples were prepared hydrothermally using previously reported procedures ${ }^{6 b, 7,8}$ For the former the co-templates cyclam and tetraethylammonium were used, whereas for $\mathrm{Cu}$ SAPO STA-7 the cyclam was replaced by the $\mathrm{Cu}^{2+}$ cyclam complex. The syntheses yielded light yellow (SAPO) and purple (CuSAPO) crystalline materials, the phase-purity of which was established by powder X-ray diffraction over a $2 \theta$ range of $5-70^{\circ}$ using a Stoe STAD $\mathrm{I} / \mathrm{P}$ diffractometer with a primary monochromator and using $\mathrm{Cu} \mathrm{K \alpha}{ }_{1}$ radiation. The morphology of the samples was examined by scanning electron microscopy using a JOEL JSM-670oF SEM with an attached Oxford INCA Energy 200 EDX analyser to determine the composition. Elemental analysis was carried out by Elemental Analysis Service, London Metropolitan University, United Kingdom.

TGA analysis was performed on a Netzsch TG1oooM in a dry air flow with a heating rate of $5{ }^{\circ} \mathrm{C} \mathrm{min}^{-1}$. Calcination of some of the as-prepared materials was performed in flowing oxygen at $823 \mathrm{~K}$ for $12 \mathrm{~h}$.

Synchrotron IR spectroscopy of individual STA-7 crystals during dehydration, calcination and rehydration experiments was carried out on the Bruker Vertex 8ov Vacuum-FTIR equipped with a Hyperion 3000 IR microscope at beamline B22 at the Diamond Light Source, Didcot, UK. ${ }^{19}$ The microscope was set-up to a resolution of $4 \mathrm{~cm}^{-1}$ at $20 \times$ magnification in transmission mode. An aperture of $10 \times 10$ or $15 \times 15 \mu \mathrm{m}^{2}$ at the sample was used for the measurements. A total of 256 scans per spectrum have been collected at $80 \mathrm{kHz}$ FTIR scanner velocity, equivalent to $30 \mathrm{~s}$ per mid-IR spectrum.

The samples were loaded onto either a zinc selenide or a calcium fluoride disc in a Linkam FTIR6oo cell - with equivalent $\mathrm{ZnSe}$ or $\mathrm{CaF}_{2}$ windows respectively - and mounted on the remote-controlled microscope stage. This cell allows the sample to be heated up to $500{ }^{\circ} \mathrm{C}$ and cooled down quickly to room temperature using water circulation around the cell. In order to remove water and combustion products the cell was continuously flushed with dry nitrogen or air during heating and cooling phases. Using the OPUS software suite $^{20}$ spectra of individual crystals with appropriate orientation with respect to the polarised synchrotron beam have been measured (Figure 2). The setup allows crystal selection by saving several individual crystal positions, so that spectra on the same crystals in the same sequence can be measured after any particular treatment. Spectra were taken over the range 400 to $4000 \mathrm{~cm}^{-1}$, with either unpolarised or polarised IR. For the latter, the direction of polarisation was chosen to be either from left to right with relation to the optical image, or from top to bottom, and crystals of STA-7 (which crystallise as elongated tetragonal prisms) were chosen that were orientated with their c-axes either 'horizontal' (left to right) or vertical (top to bottom), since the stage could not be rotated.
Holographic ZnSe wire grid polarizers were used to define the electric field direction of the outcoming IR beam after the sample.

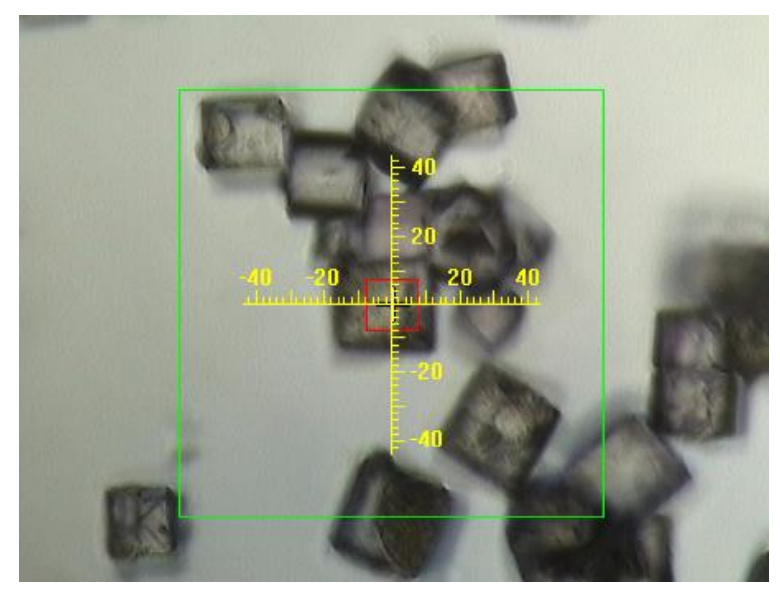

Figure 2. Optical image, taken from a screen section during microspectroscopy, in OPUS software ${ }^{20}$ indicating crystal orientation and $10 \mu \mathrm{m} \times 10 \mu \mathrm{m}$ aperture (indicated by the red square).

Absorption spectra were in each case calculated using the corresponding background, although for some crystals that were examined there were significant interference features that appear to be due to the morphology, size and orientation of the crystals with respect to their supporting plate: these could not easily be removed. For each experiment, a series of crystals was examined to ensure enough spectra to be collected without these interference fringes to give a representative set of data.

Full in situ calcination of Cu-SAPO STA-7 (rather than SAPO STA-7) was performed, because of the lower calcination temperature and shorter times required for that material. In addition, infrared microspectroscopy was used to monitor the dehydration of as-prepared and pre-calcined SAPO STA-7 and the rehydration of calcined SAPO STA-7 and calcined Cu-SAPO STA-7.

Solid-state UV-Visible spectra of as-prepared $\mathrm{Cu}$-SAPO STA-7 and samples heated at temperatures up to $250^{\circ} \mathrm{C}$ were collected by diffuse reflectance on a JACSO V-65o UV-Visible spectrophotometer equipped with a photomultiplier tube detector. A wavelength range of $400-900 \mathrm{~nm}$ was scanned with a bandwidth of $5.0 \mathrm{~nm}$ at a rate of $200 \mathrm{~nm} \mathrm{~min}^{-1}$.

High resolution powder diffraction data of a sample of as-prepared $\mathrm{Cu}$-SAPO STA-7 were collected at room temperature on station ID-31 at the ESRF (Grenoble, France) using monochromated radiation of wavelength o.80o178 A. Rietveld refinement was performed using the GSAS programs suite ${ }^{21}$ adopting as a starting model the Cu-SAPO STA-7 structure solved by single crystal diffraction ${ }^{8}$ with the 'P' sites occupied by $\mathrm{P}$ and $\mathrm{Si}$ as determined by EDX analysis. The background profile has been fitted using a shifted Chebyshev function with 34 terms while a Pseudo-Voigt function was used to fit 
the peak shape. The framework $\mathrm{P} / \mathrm{Si}-\mathrm{O}, \mathrm{Al}-\mathrm{O}, \mathrm{O}-\mathrm{O}(\mathrm{P} / \mathrm{Si})$ and $\mathrm{O}-\mathrm{O}(\mathrm{Al})$ distances were restrained to $1.52 \AA$ ( $\sigma=$ $0.025 \AA$ ), $1.72 \AA(\sigma=0.025 \AA)$, $2.50 \AA$ ( $\sigma=0.025 \AA$ ), and $2.82 \AA(\sigma=0.025 \AA)$. For the structure directing agents, $\mathrm{Cu}-\mathrm{N}, \mathrm{C}-\mathrm{N}, \mathrm{C}-\mathrm{C}$ (cyclam), N-C, C-C (TEAOH) distances have been restrained to $2.10 \AA$ ( $\sigma=0.025 \AA), 1.47 \AA$ ( $\sigma=$ $0.025 \AA), 1.40 \AA$ ( $\sigma=0.025 \AA), 1.47 \AA(\sigma=0.025 \AA)$ and $1.54 \AA$ ( $\sigma=0.025 \AA$ ) as appropriate. The isotropic atomic displacement parameters of the framework atoms have been constrained separately for each of the atom types $\mathrm{Al}, \mathrm{P} / \mathrm{Si}$ and $\mathrm{O}$. A similar approach was used for both SDAs, where all the $\mathrm{C}$ and $\mathrm{N}$ atoms in the cyclam have been constrained together as well as for all the $C$ of TEAOH. Via difference Fourier analysis it was possible to locate two water molecule $\mathrm{O}$ atoms coordinated to copper, one water molecule $\mathrm{O}$ atom within the large cage of the SAV framework, close to the centre of the 8 MR window, and another within the small cage close to the centre of the $8 \mathrm{MR}$ window. An additional carbon position within the flexible cyclam ring was also successfully refined. The occupancy, positions and thermal parameter of these atoms have been refined. Relatively high displacement parameters of the cyclam and water molecules, coordinated to the $\mathrm{Cu}^{2+}$, are due to disorder of the cyclam of the metal complex. The refinement plot and data can be found in the Supporting Information (SI).

Single crystals of as-prepared Cu-SAPO STA-7 dehydrated by heating at 150,200 and $250{ }^{\circ} \mathrm{C}$ and transferred rapidly into oil before examination have been examined by single-crystal x-ray diffraction on a Rigaku Mercury diffractometer equipped with a CCD detector using a rotating anode for $\mathrm{Mo} \mathrm{K} \alpha$ radiation. The structures were solved and refined using SHELX$97^{22}$ The framework was solved with alternating $\mathrm{Al}$ and $\mathrm{P}(\mathrm{Si})$ in the tetrahedral positions and the highest extraframework electron density maximum in the large cage was assigned to the $\mathrm{Cu}$ atom. Surrounding electron density has been assigned to the template or coordinated water. Electron density found in the smaller cage was identified as charge-balancing tetraethylammonium cations. The displacement parameters of atoms of both templates are high, due to their disorder. Refinement details and atomic positions/parameters can be found in the SI.

EPR spectra were recorded at $80 \mathrm{~K}$ on a JEOL FAzoo spectrometer equipped with an Oxford Instruments cryostat. The magnetic field was calibrated with a manganese marker. Around $20 \mathrm{mg}$ of $\mathrm{Cu} \_\mathrm{SAPO}-\mathrm{STA}-7$ was placed in a quartz EPR tube fitted with a double stopcock high vacuum adaptor. Samples were evacuated to $10^{-6}$ mbar briefly at room temperature or at various elevated temperatures as described in the text, or briefly at room temperature following exposure to air. Simulation of the powder spectra was undertaken with the programme SIM $32 .{ }^{23}$ The g- and hyperfine tensors were assumed to have axial symmetry. The parallel and perpendicular components of both were initially estimated from the experimental spectra, then varied along with the corresponding linewidths to achieve best fit of the observed spectra.

The location of the $\mathrm{Cu}^{2+}$-cyclam complex in as-prepared STA-7 has been reported previously, based on singlecrystal diffraction, although it was not possible to locate all $C$ positions unambiguously due to disorder. ${ }^{8}$ Starting from the location of the $\mathrm{CuN}_{4}$ core of the complex, a computer modeling study of the lowest energy configuration of the $\mathrm{Cu}$-cyclam complex within the larger cage of STA-7 with two, one and zero coordinated water molecules was performed in order to understand better the nature of its templating action.

Plane wave density functional theory calculations were performed using the CASTEP code (Version 6.o ${ }^{24}$ with the core orbitals replaced by norm-conserving pseudopotentials. The generalised gradient approximation (GGA) functional of Perdew, Burke and Ernzerhof (PBE) was used for the exchange correlation potential. The energy cut-off was chosen as $500.0 \mathrm{eV}$. The size of the unit cell was constrained during the calculation but all the atoms in the template and framework were allowed to move. The van der Waals interactions were included via a dispersion correction term using the Tkatchenko and Scheffler (TS) scheme. ${ }^{25}$ The convergence criteria for total energy, maximum force and maximum displacement were $2 \times 10^{-5} \mathrm{eV} /$ atom, $0.05 \mathrm{eV} / \AA ̊$, and $2 \times 10^{-3} \AA \AA$ A respectively.

\section{Results}

SAPO STA-7 and Cu-SAPO STA-7 were successfully synthesised, as shown by PXRD (SI), and the composition of the different samples was established by a combination of EDX, CHN and TGA (table I). Two batches of the Cu-SAPO STA-7 were analysed in this work, one which showed considerable intergrowth (and slightly higher $\mathrm{Cu}$ content), the second composed largely of single crystals with the typical tetragonal prismatic shape with average crystal sizes of $25 \times 35 \mu \mathrm{m}$. All spectroscopy and SXRD was performed on the single crystals, but synchrotron PXRD on the as-prepared slightly intergrown sample gave the best data on the structure of the hydrated $\mathrm{Cu}$-cyclam complex.

TGA in air indicated that the organic templates were fully removed at lower temperatures from $\mathrm{Cu}-\mathrm{SAPO}$ STA-7 than from SAPO STA-7 (SI), presumably due to a catalytic effect of the $\mathrm{Cu}^{2+}$ cations. Calcination at $400{ }^{\circ} \mathrm{C}$ for extended periods in air fully removed the organic templates, so these conditions were adopted in the in situ IR experiments. 
Table 1: Composition of the samples found by EDX, TGA and elemental analysis

\begin{tabular}{|l|l|l|l|}
\hline & SAPO STA-7 & Cu-SAPO STA-7 (IR) & $\begin{array}{l}\text { Cu-SAPO STA-7 } \\
\text { (Synchrotron PXRD) }\end{array}$ \\
\hline as-prepared & $\begin{array}{l}{[\text { cyclam }]_{1.9}[\mathrm{TEA}]_{2}} \\
\mathrm{Al}_{24} \mathrm{Si}_{6} \mathrm{P}_{18} \mathrm{O}_{96} 6.2 \mathrm{H}_{2} \mathrm{O}\end{array}$ & $\begin{array}{l}{[\mathrm{Cu}-\text { cyclam }]_{1.3}[\text { cyclam }]_{\text {o. }}[\mathrm{TEA}]_{2}} \\
\mathrm{Al}_{24} \mathrm{Si}_{8} \mathrm{P}_{16} \mathrm{O}_{96} 10.2 \mathrm{H}_{2} \mathrm{O}\end{array}$ & $\begin{array}{l}{[\mathrm{Cu}-\text { cyclam }]_{2.0}[\mathrm{TEA}]_{2}} \\
\mathrm{Al}_{24} \mathrm{Si}_{7} \mathrm{P}_{17} \mathrm{O}_{96} 8.1 \mathrm{H}_{2} \mathrm{O}\end{array}$ \\
\hline calcined & $\mathrm{H}_{6} \mathrm{Al}_{24} \mathrm{Si}_{6} \mathrm{P}_{18} \mathrm{O}_{96.0} \cdot 52.9 \mathrm{H}_{2} \mathrm{O}$ & $\mathrm{Cu}_{1.3} \mathrm{H}_{5.4} \mathrm{Al}_{24} \mathrm{Si}_{8} \mathrm{P}_{16} \mathrm{O}_{96} \cdot 46.7 \mathrm{H}_{2} \mathrm{O}$ & -- \\
\hline
\end{tabular}

The loss of the organics, cyclam from the complex and tetraethylammonium cations, is observed as a reduction in intensity of bands due to $\mathrm{C}-\mathrm{H}$ vibrational stretches $\left(2900-3100 \mathrm{~cm}^{-1}\right)$ and $\mathrm{N}-\mathrm{H}$ vibrational stretches $(3150-$ $\left.3300 \mathrm{~cm}^{-1}\right)$, whereas the generation of structural hydroxyl groups is observed by the increase of intensity, particularly at the higher temperatures $\left(375-400{ }^{\circ} \mathrm{C}\right)$, of the $\mathrm{OH}$ stretches $\left(3550-3700 \mathrm{~cm}^{-1}\right)$. There is also a reduction in the intensity of a broad band in the $3300-$ $3700 \mathrm{~cm}^{-1}$ region as the sample is heated above $150{ }^{\circ} \mathrm{C}$, due to the removal of $\mathrm{H}$-bonded water molecules.

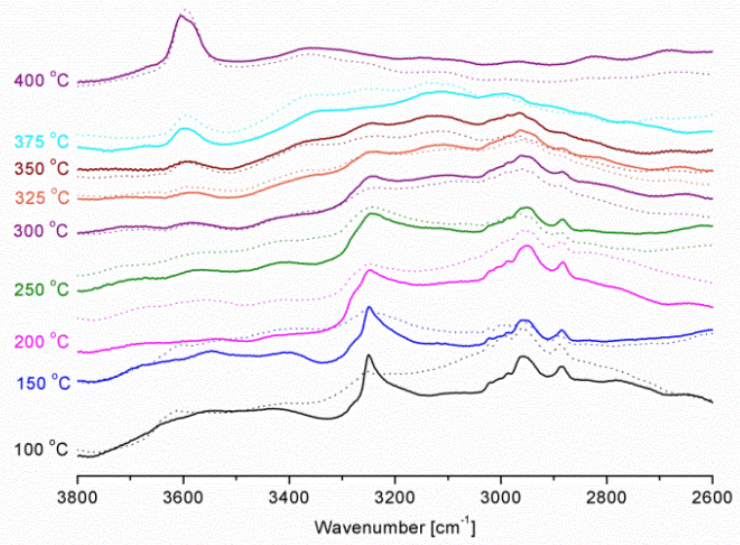

Figure 3. Microcrystal infrared spectra measured during in situ calcination of Cu-SAPO STA-7 single-crystals (solid line, polarisation parallel to $c$-axis; dashed line, polarised perpendicular to $c$-axis).

Closer examination shows that whereas the relative intensities of the $\mathrm{C}-\mathrm{H}$ stretches remain similar for the two directions of polarisation, the N-H stretch shows very strong polarisation effects, with much higher intensities observed when the radiation is polarised parallel to the (elongated) c-axis of the crystals. This indicates that the $\mathrm{N}-\mathrm{H}$ bonds (only present in the cyclam complex) are aligned nearly parallel to the $c$ axis.

As the temperature is increased up to $250^{\circ} \mathrm{C}$, at which temperature the templates are expected to remain intact (from the TGA), the sharpness of the $\mathrm{N}-\mathrm{H}$ resonance in the spectra with polarisation parallel to the $c$-axis decreases. To determine whether this is due to the thermal vibrations and changes in the complex orientation, spectra were taken after heating in dry $\mathrm{N}_{2}$ and subsequent cooling back to room temperature (SI). These show that although there is some narrowing of the band upon cooling the dehydrated crystals back to room temperature (presumably as a result of a reduction in thermal motion), there is also an overall reduction in sharpness after dehydration that is attributed to a change in average orientation of the dehydrated complex. Remarkably, if the same process of polarised synchrotron IR combined with optical microscopy is used to examine the dehydration of SAPO STA-7 microcrystals (which contain protonated cyclam rather than the $\mathrm{Cu}$-cyclam complex), the spectra do not show strong polarisation effects for the $\mathrm{N}-\mathrm{H}$ resonance, indicating that the $\mathrm{N}-\mathrm{H}$ bonds are not strongly oriented in that material (SI).

The hydroxyl groups observed at $3550-3700 \mathrm{~cm}^{-1}$ upon calcination of $\mathrm{Cu}$-SAPO STA-7 arise because the charge balance of the negatively-charged framework is from a combination of $\mathrm{Cu}^{2+}$ cations released from the cyclam complex and also from protons derived from the tetraethylammonium cations. These hydroxyl groups have been observed previously in $\mathrm{Cu}-\mathrm{SAPO}$ STA- $7^{8}$ and the bands are similar in shape (but lower in intensity) compared to those observed upon calcination of SAPO STA-7, where all charge balance in the calcined solid is achieved by protons.

The dehydration of previously calcined samples of SAPO STA-7 and Cu-SAPO STA-7 was also monitored by single crystal synchrotron IR, using unpolarised radiation. Samples were heated to $100{ }^{\circ} \mathrm{C}$ in order to remove weakly bound water, followed by heating further to $200{ }^{\circ} \mathrm{C}$ in $20{ }^{\circ} \mathrm{C}$ increments. Each temperature was kept constant for 3 minutes before the spectra were recorded. The section of the IR spectra shown in Figure 4 indicates strong IR bands in the region of $3700-3550$ $\mathrm{cm}^{-1}$ characteristic of hydroxyl groups.

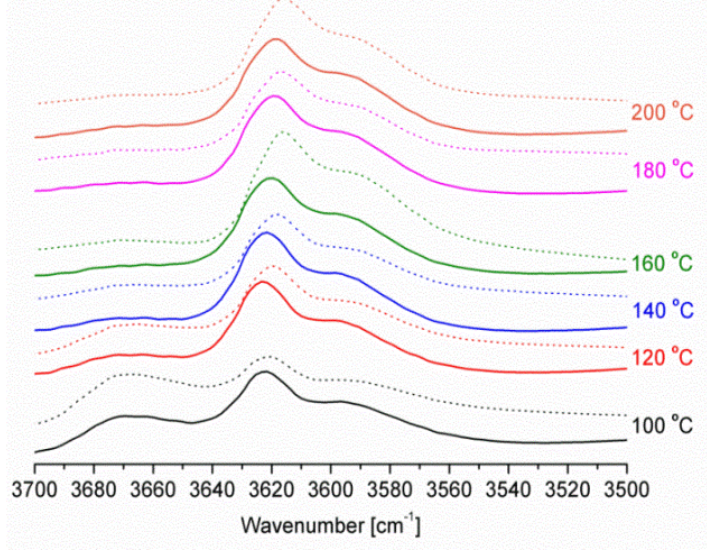

Figure 4. Unpolarised IR spectra of the dehydration of previously calcined crystals of SAPO STA-7 (dashed line) and $\mathrm{Cu}$-SAPO STA-7 (solid line). 
Initially three broad bands are present, attributed to framework hydroxyl groups $\left(3621 \mathrm{~cm}^{-1}\right.$ and $\left.3595 \mathrm{~cm}^{-1}\right)$ and physisorbed (or chemisorbed) water in the framework $\left(3670 \mathrm{~cm}^{-1}\right){ }^{26}$ Mihaleva et al. have calculated $\mathrm{OH}$ stretching frequencies in this region for isolated $\mathrm{H}_{2} \mathrm{O}$ molecules weakly hydrogen bonded to framework oxygen atoms in the related SAPO-34 structure. ${ }^{27}$ At 100 ${ }^{\circ} \mathrm{C}$, the band corresponding to the adsorbed water is almost as intense as the bands of the hydroxyl bands, but upon heating, the intensity of the water band decreases in intensity. At temperatures higher than 130 ${ }^{\circ} \mathrm{C}$, the band is completely removed and the two hydroxyl bands dominate the spectrum. These are the Brønsted acid sites (bridging hydroxyl groups $\mathrm{Si}(\mathrm{OH}) \mathrm{Al}$ ) that impart to STA-7 its activity in the MTO reaction. ${ }^{9}$

Previous IR studies of calcined dehydrated SAPO STA-7 powders have shown very similar spectra of hydroxyl groups, ${ }^{28}$ and the breadth of the IR bands together with the crystallographic complexity of STA-7 has prevented unambiguous assignment to specific crystallographic sites. What is remarkable is that the same information can so readily be obtained from a single crystal of the material. Furthermore, the hydroxyl bands show a shift to lower wavenumber as the temperature is raised, so that the band maximum is found at $3621 \mathrm{~cm}^{-1}$ at $100{ }^{\circ} \mathrm{C}$ and with increasing temperature the maximum absorption moves to $3615 \mathrm{~cm}^{-1}$ at $400{ }^{\circ} \mathrm{C}$. This decrease can be attributed to thermal expansion of the lattice.

To confirm that the band at higher wavenumber is from adsorbed water, a separate experiment was performed in which $\mathrm{D}_{2} \mathrm{O}$ was introduced into the $\mathrm{N}_{2}$ stream passing over dehydrated $\mathrm{Cu}-\mathrm{SAPO}$ STA-7 at $100{ }^{\circ} \mathrm{C}$ (Figure 5). There is a reduction in the bridging hydroxyl band at $3621 \mathrm{~cm}^{-1}$ and a simultaneous increase in the corresponding bridging deuteroxyl band (at $2670 \mathrm{~cm}^{-1}$ ). A shoulder at $2725 \mathrm{~cm}^{-1}$ is the OD stretching vibration of an adsorbed $\mathrm{D}_{2} \mathrm{O}$ molecule, corresponding to the 3670 $\mathrm{cm}^{-1}$ band of adsorbed $\mathrm{H}_{2} \mathrm{O}^{29}$

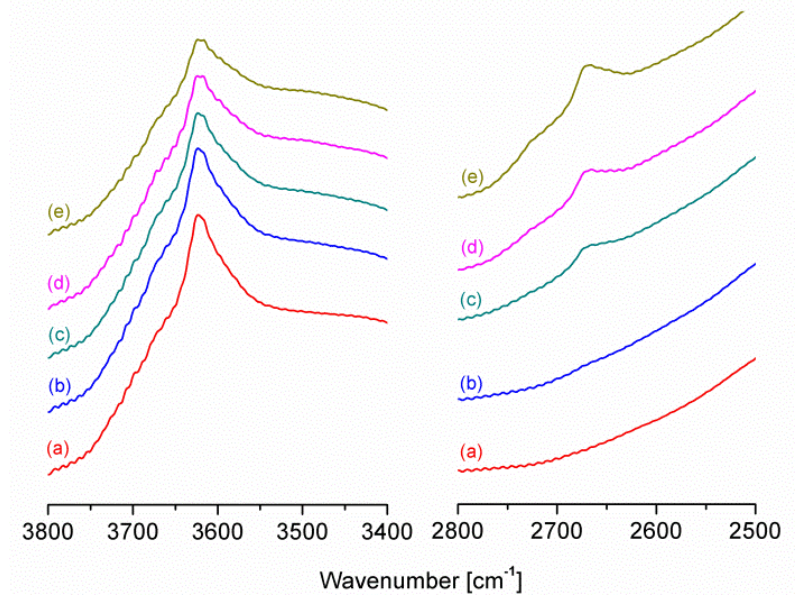

Figure 5. Unpolarised microcrystal IR spectra measured after injection of $\mathrm{D}_{2} \mathrm{O}$ in the dry $\mathrm{N}_{2}$ flowing over calcined and dehydrated $\mathrm{Cu}-\mathrm{SAPO}$ STA-7 at $100{ }^{\circ} \mathrm{C}$. ((a) dehydrated; (b) - (e) $5 \mu \mathrm{L}, 15 \mu \mathrm{L}, 25 \mu \mathrm{L}$ and $45 \mu \mathrm{L} \mathrm{D} 2 \mathrm{O}$ added to flowing N2 gas stream.)
These results show that it is possible to observe the activation and subsequent hydration of a single crystal of the Cu-SAPO STA-7 by IR microspectroscopy. The use of polarised synchrotron light IR microscopy also gives information on the orientation of the $\mathrm{Cu}$-cyclam complex. This is strongly relevant to the way in which the complex acts as a structure directing agent, so the orientation of the complex and its state of hydration was investigated further by means of complementary diffraction and spectroscopy.

\section{Orientation and Hydration State of the Cu-complex template}

Previous work had demonstrated that $\mathrm{Cu}^{2+}$-cyclam complexes were present in the larger cages of STA-7, and single crystal XRD of as-prepared Cu-SAPO STA-7 had determined the positions of the $\mathrm{Cu}^{2+}$ cation and coordinating $\mathrm{N}$ atoms, as well as approximate positions of $\mathrm{C}$ atoms in the ethylene and propylene chains, but no $\mathrm{H}$ positions or coordinating water molecules were located. ${ }^{9}$ Nevertheless, the material changes colour upon dehydration at temperatures below which any template decomposition occurs, from purple via pink to yellow and then returns to pink upon exposure to moist air, suggesting that the complex has coordinated water in the as-prepared $\mathrm{Cu}$-SAPO. In order to understand the dehydration process, and thereby the state of the complex during synthesis, a combination of powder Xray diffraction and spectroscopies were employed.

Refinement of the structure of a sample of as-prepared $\mathrm{Cu}-\mathrm{SAPO}$ STA-7 from high resolution synchrotron PXRD data indicated that it was possible to locate four positions for $\mathrm{O}$ atoms of water molecules (in addition to the silicoaluminophosphate framework, the copper cyclam complex (with disordered $C$ positions) and the tetraethylammonium cations). Two of these water $\mathrm{O}$ atoms were coordinated, fully occupied, to the two different sides of the complex, at chemically reasonable distances from the $\mathrm{Cu}^{2+}$ cation, $\mathrm{Cu}-\mathrm{O}_{\mathrm{w} 1}=2.268 \AA$ and $\mathrm{Cu}-\mathrm{O}_{\mathrm{w} 2}=2.139 \AA$ (Figure 6). Further positions were located within the large cage close to the centre of the $8 \mathrm{MR}$ and within the small cage close to the centre of the $8 \mathrm{MR}$, with occupancies of 0.68 and 0.47 respectively. Single crystal diffraction of samples heated at $150{ }^{\circ} \mathrm{C}$ and $200{ }^{\circ} \mathrm{C}$ did not give unambiguous locations for adsorbed water molecules or the positions of the template atoms, but was able to locate the $\mathrm{CuN}_{4}$ core of the copper cyclam complex, confirming that the complex remained intact. It was not possible to locate this $\mathrm{CuN}_{4}$ core in the material calcined at $250{ }^{\circ} \mathrm{C}$, suggesting that template decomposition had begun under these conditions. 


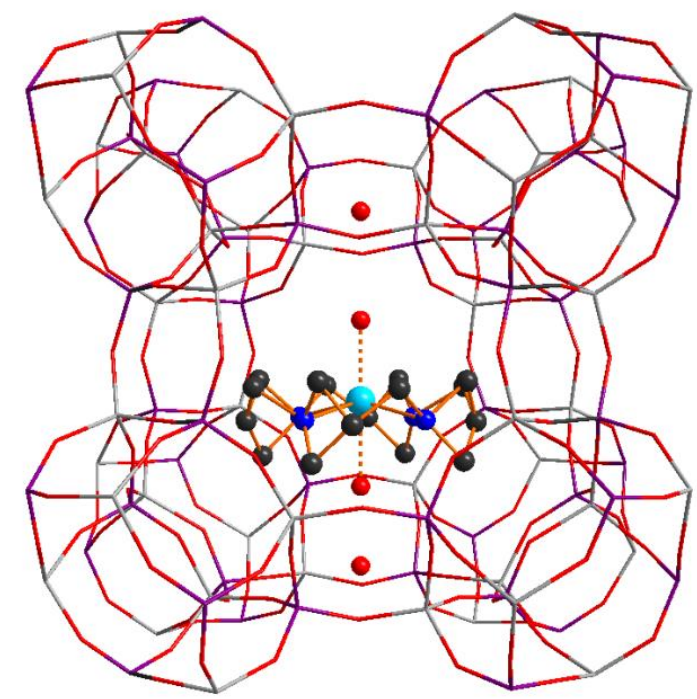

Figure 6. Refined structure of the $\mathrm{Cu}^{2+}$-cyclam complex within the large cage of STA-7 viewed along [o1o]. All C and $\mathrm{N}$ positions of the disordered cyclam are shown ( $\mathrm{C}$ in black, $\mathrm{N}$ in dark blue) as well as $\mathrm{O}$ atoms (red) of water molecules coordinated to $\mathrm{Cu}$ (light blue) and at other sites in the structure.

UV-visible and EPR spectroscopies were used to follow the dehydration process. EPR spectra were measured on an as-prepared sample evacuated for a few seconds at room temperature, evacuated at $150{ }^{\circ} \mathrm{C}$ for $1 \mathrm{~h}$ and evacuated at $150{ }^{\circ} \mathrm{C}$ for $16 \mathrm{~h}$. Following these successive heat treatments, the sample was exposed to air overnight then briefly evacuated again before measurement.

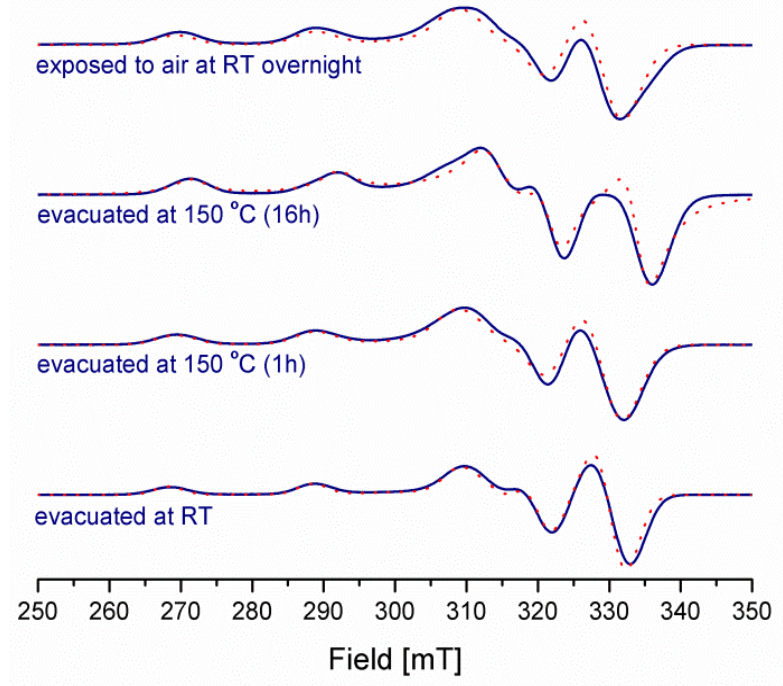

Figure 7. Electron spin resonance spectra of $\mathrm{Cu}$-SAPO STA7 samples collected at different temperatures under vacuum ((a) room temperature, (b) $150{ }^{\circ} \mathrm{C}$ for $1 \mathrm{~h}$, (c) $150{ }^{\circ} \mathrm{C}$ for $16 \mathrm{~h}$ and (d) exposed to moist air at room temperature overnight (solid line: experimental, dashed line: simulated).

The EPR spectra are typical of $\mathrm{Cu}^{2+}$-cyclam complexes, as reported previously. ${ }^{30}$ Three distinct signals can be identified. The spectrum of the as-prepared sample could be fitted with axial g- and hyperfine tensor components: $\mathrm{g}\|=\mathbf{2 . 1 7 5}, \mathrm{A}\|=205 \times 10^{-4} \mathrm{~cm}^{-1}, \mathrm{~g} \perp=\mathbf{2 . 0 3 3}$, $\mathrm{A}^{\perp}=36 \times 10^{-4} \mathrm{~cm}^{-1}$. After evacuation at $150{ }^{\circ} \mathrm{C}$ for 1 hour there is a small but significant decrease in $\mathrm{A} \|$ (to $198 \mathrm{x}$ $10^{-4} \mathrm{~cm}^{-1}$ ), most evident as a shift of the low field hyperfine components to higher field. $\mathrm{A}^{\perp}$ was unchanged, and $\mathrm{g} \perp$ increased to 2.036. After evacuation at $150{ }^{\circ} \mathrm{C}$ for 16 hours a new signal was obtained with $\mathrm{g} \|$ $=2.147, \mathrm{~A} \|=210 \times 10^{-4} \mathrm{~cm}^{-1}, \mathrm{~g} \perp=2.025$ and $\mathrm{A}^{\perp}=42 \times 10^{-4}$ $\mathrm{cm}^{-1}$. The changes in shape of the powder spectrum are clearly evident. On subsequent exposure to air overnight the signal reverted to that obtained after brief evacuation at $150{ }^{\circ} \mathrm{C}$. This signal was simulated with identical parameters to that in Figure 7. These changes could be reversed by further heating at $150{ }^{\circ} \mathrm{C}$ or higher, but the original spectrum of the as-prepared sample could not be restored by prolonged exposure to air. The changes in the EPR spectra may be interpreted in terms of the partial or complete dehydration of the $\mathrm{Cu}$ complex starting from an octahedral $\mathrm{Cu}$ environment in $\left[\mathrm{Cu}(\text { cyclam })\left(\mathrm{H}_{2} \mathrm{O}\right)_{2}\right]^{2+}$, followed by loss of coordinated water to $[\mathrm{Cu}(\text { cyclam })]^{2+}$ after extended heating at $150^{\circ} \mathrm{C}$. This gradual water loss is in accordance with the TGA shown (ESI). Allowing the sample dehydrated at $150{ }^{\circ} \mathrm{C}$ to rehydrate upon contact with moist air resulted in the spectra changing back to an intermediate state of hydration, $\left[\mathrm{Cu}(\text { cyclam })\left(\mathrm{H}_{2} \mathrm{O}\right)\right]^{2+}$.

The g- and hyperfine tensor components of all 3 signals are typical of axial $\mathrm{Cu}(\mathrm{II})$ complexes with the unpaired electron in the $d_{x 2-y 2}$ orbital. The small changes in EPR parameters on dehydration indicate that the strong equatorial ligand field in the as-prepared material is retained after prolonged heating at $150{ }^{\circ} \mathrm{C}$. Nevertheless, subtle effects of removal (or partial replacement) of axial ligands are seen. A similar insensitivity to axial ligands has been reported for $\mathrm{Cu}^{2+}$-cyclam grafted onto mesoporous silica. ${ }^{31}$

The colour changes observed upon dehydration are also suggestive of coordination changes at the $\mathrm{Cu}^{2+}$ cation. $\mathrm{UV}$-visible spectra were therefore measured on samples dehydrated at different temperatures. Although facilities were not available to allow spectra to be run under a controlled environment, the samples were measured within minutes of removal from the furnace and it was found that colour changes due to rehydration were slow. Spectra were then taken after the heated samples were allowed to rehydrate in moist air over an extended period. 


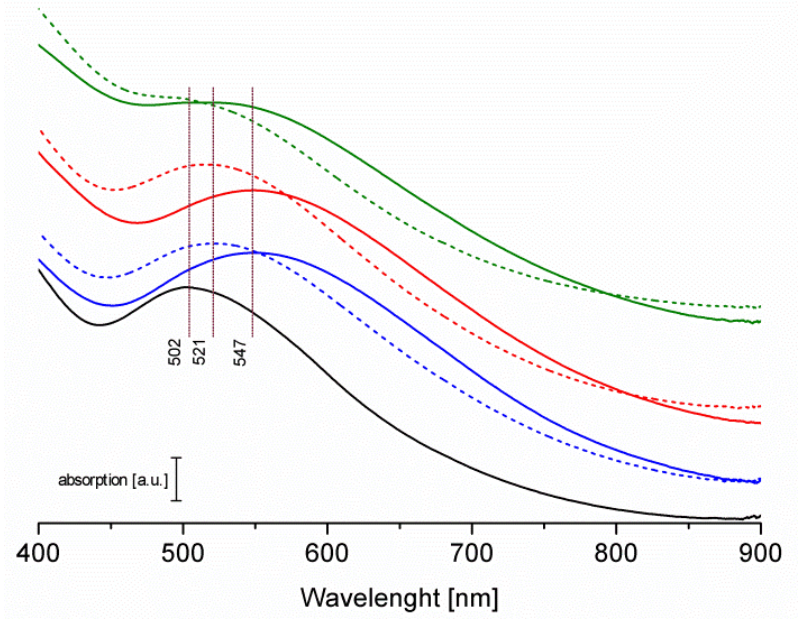

Figure 8. Solid-state UV-Visible spectra for dehydrated and rehydrated samples of Cu-SAPO STA-7. As-prepared, black line; heated at $150{ }^{\circ} \mathrm{C}$, blue line, then allowed to rehydrate at room temperature (dotted blue); heated at $200{ }^{\circ} \mathrm{C}$ and rehydrated (continuous and dotted red lines); heated at 250 ${ }^{\circ} \mathrm{C}$ (green lines).

The as-prepared, fully hydrated material has an absorption maximum at $502 \mathrm{~nm}$. Upon dehydration at $150{ }^{\circ} \mathrm{C}$ for $12 \mathrm{~h}$, the maximum shifts to $547 \mathrm{~nm}$ (the sample appears yellow), which is thought to correspond to the fully dehydrated $\mathrm{Cu}$-cyclam complex. After rehydrating the sample for $12 \mathrm{~h}$ in moist air, the maximum shifts back towards the initial position to a value of $521 \mathrm{~nm}$. Similar effects are observed after heating at 200 and $250{ }^{\circ} \mathrm{C}$, although by $250{ }^{\circ} \mathrm{C}$ it may be that some decomposition of the complex is occurring. These results may be interpreted as an octahedral $\left[\mathrm{Cu}(\text { cyclam })\left(\mathrm{H}_{2} \mathrm{O}\right)_{2}\right]^{2+}$ in the as-prepared form losing all its water to give the fully dehydrated form and then regaining one water to give $\left[\mathrm{Cu}(\mathrm{cyclam})\left(\mathrm{H}_{2} \mathrm{O}\right)\right]^{2+}$.

With the working model that the hydrated complex is present in the as-prepared Cu-SAPO STA-7, which loses water upon heating to give the dehydrated complex, the strong anisotropy observed in the N-H stretch by the polarised IR spectroscopy can be related to the orientation of this complex in its different stages of dehydration. In order to examine this further, computational modelling of the $[\mathrm{Cu}-\mathrm{cyclam}]^{2+}$, $\left[\mathrm{Cu}(\text { cyclam })\left(\mathrm{H}_{2} \mathrm{O}\right)\right]^{2+}$ and $\left[\mathrm{Cu}(\text { cyclam })\left(\mathrm{H}_{2} \mathrm{O}\right)_{2}\right]^{2+}$ complexes within the larger cage of the SAPO STA-7 framework was performed. The energy minimised locations of these complexes are shown in Figure 9. In each case, they indicate an alignment of the $\mathrm{N}-\mathrm{H}$ bonds close to parallel to the $c$-axis, corresponding to the long axis of the elongated tetragonally prismatic crystals.
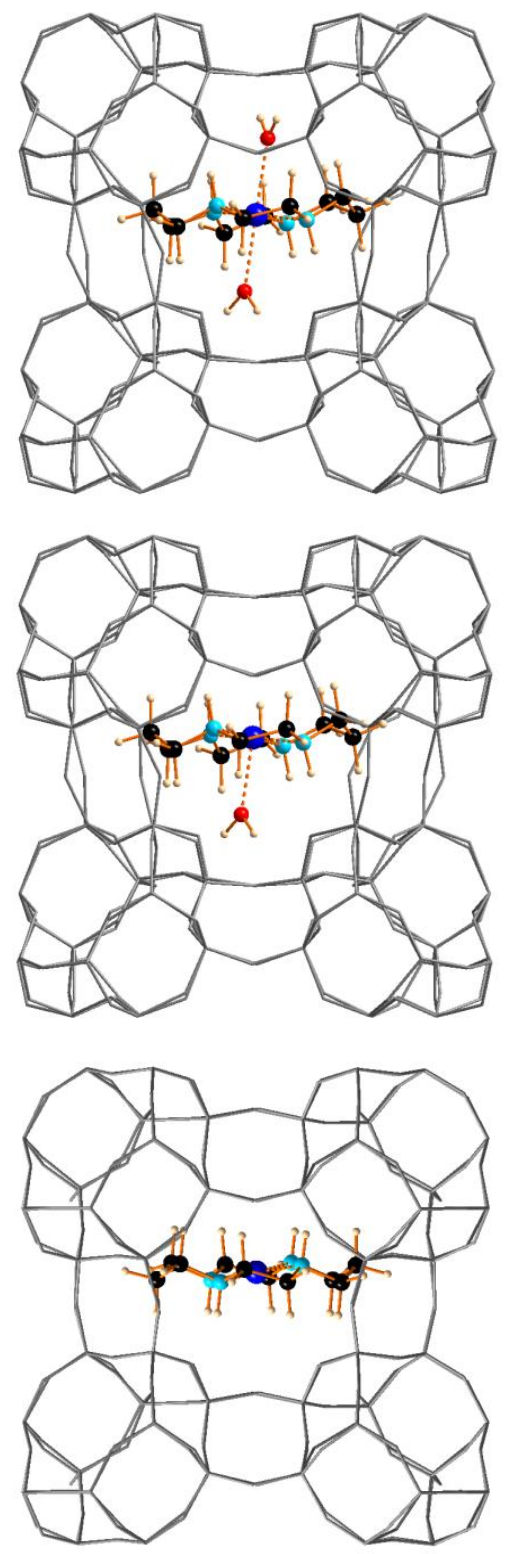

Figure 9. Energy-minimised position of $\mathrm{Cu}$-cyclam di-, mono- and dehydrated complex (top to bottom respectively) in the large cage of STA-7 viewed along [010] (framework grey, C black, $\mathrm{N}$ cyan, $\mathrm{O}$ red, $\mathrm{Cu}$ blue, $\mathrm{H}$ grey).

The total binding energy value for the dihydrate complex is $-3.317 \mathrm{eV}$ whereas the monohydrate model gives a binding energy of $-3.387 \mathrm{eV}$. For the dehydrated complex, the binding energy is $-3.282 \mathrm{eV}$. This shows that the five-coordinate $\mathrm{Cu}^{2+}$-cyclam complex with a single water molecule bound is favourable by $0.07 \mathrm{eV}$ $\left(8.7 \mathrm{~kJ} \mathrm{~mol}^{-1}\right)$ compared with the six-coordinate complex with two coordinating water molecules bound. It is also $0.105 \mathrm{eV}\left(13.1 \mathrm{~kJ} \mathrm{~mol}^{-1}\right)$ more favourable than the dehydrated four-coordinate complex. This is consistent with the UV-vis spectra, which do not indicate a full rehydration from the dehydrated state in moist air.

A picture therefore emerges of the $\mathrm{Cu}^{2+}$-cyclam complex that is the co-template for SAPO STA-7 in the direct synthesis of $\mathrm{Cu}-\mathrm{SAPO}$ STA-7. The complexation of the 
copper cation acts to lock the cyclam into a configuration in the large cage, the energy-minimum position of which has all $\mathrm{N}-\mathrm{H}$ bonds oriented approximately parallel to the c-axis, so that strong polarisation effects are observed in the polarised synchrotron IR spectra. Synchrotron X-ray powder diffraction indicates that the complex includes two coordinated water molecules in the as-prepared state, so that the structure directing agent is the dihydrated complex. Complementary EPR and UV-visible spectroscopy indicate that these coordinated water molecules are lost upon heating for extended periods at $150{ }^{\circ} \mathrm{C}$ and above. In situ microcrystal polarised synchrotron IR indicates that the complex retains a high degree of orientation in the cages of STA-7 during progressive dehydration: computational simulation of the orientation of the copper cyclam is consistent with this observation. The removal of the cyclam and tetraethylammonium cations occurs upon heating to $400{ }^{\circ} \mathrm{C}$ in air, to leave the active catalyst, with dispersed copper cations and bridging hydroxyl groups distributed throughout the structure. This activation is readily observed by in situ microcrystal synchrotron IR spectroscopy.

\section{Conclusion}

These measurements show that synchrotron IR microcrystal spectroscopy combined with optical microscopy can successfully be applied to the investigation of microporous catalysts. In particular, IR spectra of good quality have been measured with short data collection times on crystals of $\mathrm{Cu}$-SAPO STA-7 around $25-35 \mu \mathrm{m}$ in dimension and have given detailed insights into the templating and calcination processes. Polarised IR measurements on crystals of well-defined elongated tetragonal prismatic morphology enables the orientation of the copper cyclam co-template to be established. Combining these in situ IR results with ESR and UV-visible spectroscopic measurements, X-ray diffraction and computational methods gives detailed insight into the behaviour of the copper cyclam during the synthesis of the material and its removal upon calcination to give a catalyst active for the selective catalytic reduction of $\mathrm{NO}$ with $\mathrm{NH}_{3}$.

\section{ACKNOWLEDGMENT}

We gratefully acknowledge the EPSRC and Johnson Matthey for financial support. We acknowledge Diamond Light Source for time on beamline B22 under Proposals SM6623-1 and SM8875-1 and the ESRF at Grenoble (beamline ID31) and Professor A. Fitch for synchrotron PXRD beamtime and data collection. We also acknowledge Prof. Dr. Alexandra M. Z. Slawin for collection of single-crystal data, Mrs. Sylvia Williamson for carrying out TGAs and Mr. Stephen Boyer for Elemental Analysis.

\section{AUTHOR INFORMATION}

\section{Corresponding Author}

*Email: paw2@st-andrews.ac.uk

\section{Present Address}

† The Research Institute of Theoretical and Applied Physical Chemistry, National University of La Plata CONICET, Sucursal 4 Casilla de Correo 16, 1900 La Plata, Argentina.

\section{References}

[1] (a) Stöcker, M. Microporous Mesoporous Mater. 1999, 29, 3-48. (b) Haw, J.; Song, W.; Marcus, D. M. Acc. Chem. Res. 2003, 36, 317-326.

[2] (a) Iwamoto, M.; Furukawa, H.; Mine, Y.; Uemura, F.; Mikuriya, S. I.; Kagawa, S. J. Chem. Soc. Chem. Commun. 1986, 1272-1273. (b) Iwamoto, M.; Yahro, H.; Tanda, K,; Mizuno, N.; Mine, Y.; Kagawa, S. J. Phys. Chem. 1991, 95, 3727-3730. (c) Moden, B.; Da Costa, P.; Fonfe, B.; Lee, D. K.; Iglesia, E. J. Catal. 2002, 209, 75-86. (d) Brandenberger, S.; Krocher, O.; Tissler, A.; Althoff, R,; Catal. Rev. Sci. Eng. 2008, 50, 492-531. (e) Kwak, J. H.; Tonkyn, R. G; Kim, D. H.; Szanyi, J.; Peden, C. H. F. J. Catal. 2010, 275, 187-190. (f) Korhonen, S. T.; Fickel, D. W.; Lobo, R. F.; Weykhuysen, B. M.; Beale, A.M. Chem. Commun. 2011, 47, 80o-802. (g) Fickel, D;. D'Addio, E.; Lauterbach, J. A.; Lobo, R.F. Appl. Catal. B Environ. 2011, 102, 441-448.

[3] Lok, B. M.; Messina, C. A.; Patton, R. L.; Gajek, R. T.; Cannan, T. R.; Flanigen, E. M. J. Am. Chem. Soc. 1984, 106, 6092-6093.

[4] (a) Dahl, I. M.; Kolboe, S. J. Catal. 1996, 161, 304-309. (b) Hereijgers, B. P. C.; Bleken, F.; Nilsen, M. H.; Svelle, S.; Lillerud, K.-P.; Bjorgen, m.; Weckhuysen, B. M.; Olsbye, U. J. Catal. 2009, 264, 77-87. (c) Wragg, D. S.; Brien, M. G. O.; Bleken, F. L.; Di Michiel, M.; Olsbye, U.; Fjellvag, H. Angew. Chem. Int. Ed. 2012, 51, 7956 - 7959. (d) Qian, Q.; RuizMartinez, J.; Mokhtar, M.; Asiri, A. M.; Al-Thabaiti, S.A.; Basahel, S. N.; van der Bij, H. E.; Kornatowski, J.; Weckhuysen, B. M. Chem. Eur. J. 2013, 19, 11204-11215.

[5] (a) Ishihara, T.; Kagawa, M.; Hadama, F.; Takita, Y. J. Catal. 1997, 169(1), 93-102. (b) Xue, J.; Wang,X.; Qi, G.; Wang, J.; Shen, M.; Li, W. J. Catal. 2013, 297, 56-64. (c) Fan, S.K.; Xue, J. J.; Yu, T.; Fan, D.Q.; Hao, T.; Shen, M. Q.; Li, W. Cat. Sci. Technol. 2013, 3, 2357-2364.

[6] (a) Wright, P. A.; Maple, M.J.; Slawin, A. M. Z.; Patinec, V.; Aitken, R. A.; Welsh, S.; Cox, P. A. J. Chem. Soc., Dalton Trans. 200o, 8, 1243-1248. (b) Castro, M.; Garcia, R.; Warrender, S. J.; Wright, P. A.; Cox, P. A.; Fecant, A.; MellotDraznieks, C.; Bats, N. Chem. Commun. 2007, 3470-3472.

[7] Castro, M.; Warrender, S. J.; Wright, P. A.; Apperley, D. C.; Belmabkhout, Y.; Pirngruber, G.; Min, H.-K.; Park, M. B.; Hong, S. B. J. Phys. Chem. C 2009, 113, 15731-15741.

[8] Picone, A. L.; Warrender, S. J.; Slawin, A. M. Z.; Dawson, D. M.; Ashbrook, S. E.; Wright, P. A.; Thompson, S. P.; Gaberova, L.; Llewellyn, P. L.; Moulin, B.; Vimont, A.; Daturi, M.; Park, M. B.; Sung, S. K.; Nam, I; Hong, S. B. Microporous Mesoporous Mater. 2011, 146, 36-47.

[9] Deka, U., I. Lezcano-Gonzalez; Warrender, S. J.; Picone, A. L.; Wright, P. A.; Weckhuysen, B. M.; Beale, A. M. Microporous Mesoporous Mater. 2013, 166, 144-152.

[10] Martinez-Franco, R.; Moliner, M.; Franch, C.; Kustov, A.; Corma, A. Appl. Catal. B - Env. 2012, 127, 273-280.

[11] Ren, L. M.; Zhu, L. F.; Yang, C. G.; Chen, Y. M.; Sun, Q.; Zhang, H. Y.; Li, C. J.; Nawaz, F.; Meng, X. J.; Xiao, F. S. Chem. Commun. 2011, 47, 9789-9791. 
[12] Martinez-Franco, R.; Moliner, M.; Thogerson, J. R.; Corma, A. ChemCatChem DOI:10.1002/cctc.201300141

[13] (a) Stavitski, E.; Weckhuysen, B. M. Chem. Soc. Rev. 2010, 39, 4615-4625. (b) Schnabel, K.-H., Finger, G.; Kornatowski, J.; Loeffler, E.; Peuker, C.; Pilz, W. Microporous Mater. 1997, 11, 293-302.

[14] (a) Qian, Q.; Mores, D.; Kornatowski, J.; Weckhuysen, B. M. Microporous Mesoporous Mater. 2011, 146, 28-35. (b) Karwacki, L.; Weckhuysen, B. M. Phys. Chem. Chem. Phys., 2011, 13, 3681-3685.

[15] (a) Tzoulaki, D.; Heinke, L.; Castro, M.; Cubillas, P.; Anderson, M. W.; Zhou, W.; Wright, P. A.; Kärger, J. J. Am. Chem. Soc. 2010, 132, 11665-11670; (b) Bonilla, M. R.; Titze, T.; Schmidt, F.; Mehlhorn, D,; Chmelik, C.; Vialiullin, R.; Bhatia, S. K.; Kaskel, S.; Ryoo, R.; Kärger, J. Materials, 2013, 6, 2662-2688

[16] (a) Stavitski, E.; Kox, M. H. F.; Swart, I.; de Groot, F. M. F.; Weckhuysen, B. M. Angew. Chem. Int. Ed. 2oo8, 47, 35433547. (b) Stavitski, E., Pidko, E. A..; Kox, M. H. F.; Hensen, E. J. M.; van Santen, R. A.; Weckhuysen, B. M. Chem. Eur. J. 2010, 16, 9340-9348.

[17] Popescu, S. C.; Thomson, S.; Howe, R. F. Phys. Chem. Chem. Phys. 2000, 3, 111-118.

[18] Schüth, F.; Demuth, D.; Zibrowius, B.; Kornatowski, J.; Finger, G. J. Am. Chem. Soc. 1994, 116, 1090-1095.

[19] Cinque, G.; Frogley, M. D.; Wehbe, K.; Filik, J.; Pijanka, J. Synchrotron Radiation News, 2011, 24, 24-33

[20] OPUS software 7.0 (2011), Bruker Optik GmbH, Germany.

[21] General Structure Analysis System (GSAS), A.C. Larson, R.B. Von Dreele (1994), Los Alamos National Laboratory, USA.

[22] Sheldrick, G. M. Acta Cryst. 2oo8, A64, 112-122.

[23] Spalek, T.; Pietrrzyk, P.; Sojka, Z.; J. Chem. Inform. Model. 2005, 45, 18-29.

[24] Clark, S. J.; Segall, M. D.; Pickard, C. J.; Hasnip, P. J.; Probert, M. I. J.; Refson, K.; Payne, M. C. Z. Kristallogr. 2005, 220, 560-570.

[25] Tkatchenko, A.; Scheffler, M. Phys. Rev. Lett. 2009, 102, 073005

[26] Marchese, L.; Chen, J.; Wright, P. A.; Thomas, J. M. J. Phys. Chem. 1993, 97, 8109-8112.

[27] Mihaleva, V. H.; van Santen, R. A.; Jansen, A. P. J.; J. Chem. Phys. 2004, 120, 9212-9222.

[28] Déroche, I.; Maurin, G.; Llewellyn, P.; Castro, M.; Wright, P. A.; Bejblova, M.; Cejka, J. Stud. Surf. Sci. Catal. 2007, 170, 1660-1665.

[29] Zubkov, S. A.; Kustov, L. M.; Kazansky, V. B.; Girnus, I.; Fricke, R., J. Chem. Soc. Farad. Trans. 1991, 87, 897-90o.

[30] Dong, Y.; Lawrance, G. A.; Lindoy, L. F.; Turner, P. Dalton Trans. 2003, 8, 1567-1576.

[31] Gooubert-Renaudin, S.; Etienne, M.; Brandes, S.; Meyer, M.; Denat, F.; Lebeau, B.; Walcarius, A. Langmuir 2009, 25, 9804-9813. 